\title{
Extracellular Vesicles Derived from Human Umbilical Cord Perivascular Cells Improve Functional Recovery in Brain Ischemic Rat via the Inhibition of Apoptosis
}

\author{
Elham Seifali ${ }^{1}$, Gholamreza Hassanzadeh ${ }^{1}$, Marzieh Mahdavipour ${ }^{1}$, \\ Keywan Mortezaee ${ }^{2}$, Ashraf Moini ${ }^{3,4,5}$, Leila Satarian ${ }^{6}$, Faezeh Shekari ${ }^{7}$, \\ Abdoreza Nazari ${ }^{7}$, Shabnam Movassaghi ${ }^{8}$ and Mohammad Akbari ${ }^{{ }^{*}}$
}

\begin{abstract}
${ }^{1}$ Department of Anatomy, School of Medicine, Tehran University of Medical Sciences, Tehran, Iran;
${ }^{2}$ Department of Anatomy, School of Medicine, Kurdistan University of Medical Sciences, Sanandaj, Iran; ${ }^{3}$ Department of Gynecology and Obstetrics, School of Medicine, Tehran University of Medical Science, Tehran, Iran; ${ }^{4}$ Department of Endocrinology and Female Infertility, Reproductive Biomedicine Research Center, Royan Institute for Reproductive Biomedicine, ACECR, Tehran, Iran; ${ }^{5}$ Breast Disease Research Center (BDRC), Tehran University of Medical Sciences, Tehran, Iran; ${ }^{6}$ Department of Brain and Cognitive Science, Cell Science Research Center, Royan Institute for Stem Cell Biology and Technology, ACECR, Tehran, Iran; ${ }^{7}$ Department of Stem Cells and Developmental Biology, Cell Science Research Center, Royan Institute for Stem Cell Biology and Technology, ACECR, Tehran, Iran; ${ }^{8}$ Department of Anatomy and cognitive neuroscience, School of Medicine, Tehran Medical Sciences Branch, Islamic Azad University, Tehran, Iran
\end{abstract}

Received 6 October 2019; accepted 11 January 2020; published online 25 July 2020

\begin{abstract}
Background: Ischemic stroke, as a health problem caused by the reduced blood supply to the brain, can lead to the neuronal death. The number of reliable therapies for stroke is limited. MSCs exhibit therapeutic achievement. A major limitation of MSC application in cell therapy is the short survival span. MSCs affect target tissues through the secretion of many paracrine agents including EVs. This study aimed to investigate the effect of HUCPVCsderived EVs on apoptosis, functional recovery, and neuroprotection. Methods: Ischemia was induced by MCAO in male Wistar rats. Animals were classified into sham, MCAO, MCAO + HUCPVC, and MCAO + EV groups. Treatments began at two hours after ischemia. Expressions of apoptotic-related proteins (BAX/BCl-2 and caspase3 and -9), the amount of TUNEL-positive cells, neuronal density (MAP2), and dead neurons (Nissl staining) were assessed on day seven post MCAO. Results: Administration of EVs improved the sensorimotor function $(p<0.001)$ and reduced the apoptotic rate of $\mathrm{Bax} / \mathrm{Bcl}-2$ ratio $(p<0.001)$, as well as caspases and TUNEL-positive cells $(p<$ 0.001 ) in comparison to the MCAO group. EV treatment also reduced the number of dead neurons and increased the number of $\mathrm{MAP2}^{+}$cells in the IBZ $(p<0.001)$, as compared to the MCAO group. Conclusion: Our findings showed that HUCPVCs-derived EVs are more effective than their mother's cells in improving neural function, possibly via the regulation of apoptosis in the ischemic rats. The strategy of cell-free extracts is, thus, helpful in removing the predicaments surrounding cell therapy in targeting brain diseases. DOI: 10.29252/ibj.24.6.342
\end{abstract}

Keywords: Apoptosis, Extracellular vesicles, Ischemia, Middle cerebral artery

Corresponding Author: Mohammad Akbari

Department of Anatomy, Tehran University of Medical Sciences, Tehran, Iran; Tel. : (+98-912) 5841180; E-mail: akbarimo@tums.ac.ir

List of Abbreviations:

Bcl-2, B-cell lymphoma-2; DAB, 3,3'-diaminobenzidine; DAPI, 4,6-Diamidino-2-phenylindole dihydrochloride; DLS, dynamic light scattering; EBST, elevated body swing test; EV, extracellular vesicles; HUCPVCs, human umbilical cord perivascular cells; IBZ, ischemic boundary zone; IHC, immunohistochemistry; MAP2, microtubule-associated protein 2; MCAO, middle cerebral artery occlusion; MSC, mesenchymal stem cells; qRT-PCR, quantitative real-time PCR; SCl, spinal cord injury; SEM, scanning electron microscopy; TTC, triphenyltetrazolium chloride; TUNEL, terminal deoxynucleotidyl transferase dUTP nick end labeling 


\section{INTRODUCTION}

$\mathrm{S}$ troke is a life-threatening cerebrovascular disease caused by the reduction of bloodstream to an area of the brain, leading to neurological failure and fatality ${ }^{[1,2]}$. Following cerebral ischemia, two zones are distinguishable in the brain. The core area experiences irreversible neuronal death ${ }^{[3]}$. The IBZ is at infarction risk; however, timely therapeutic intervention may prevent apoptosis and neuronal death $^{[4]}$. Ischemia is characterized by a series of molecular events, including extreme production of free radicals and membrane depolarization that may lead to apoptosis in many brain cells $\mathrm{B}^{[3,5]}$.

Family members of the Bcl-2 regulate apoptosis by managing apoptotic signals ${ }^{[6]}$. Two members of this family are Bcl-2 and Bax. Bcl-2 is an anti-apoptotic protein that restrains the activity of $\mathrm{Bax}^{[7]}$. Bax is an essential apoptosis factor that promotes the activation of caspase enzymes, resulting in the activation of apoptosis and cellular disassembly in response to the early signals of apoptosis ${ }^{[8]}$. Caspase-mediated cell death may occur in many types of brain cells and cause neuronal injury ${ }^{[9]}$.

In recent decades, MSCs have been used for repairing the central nervous system diseases in preclinical and clinical settings ${ }^{[10,11]}$. Most MSC effects are paracrine and may exert through the secretion of nano-sized particles, called EVs ${ }^{[12,13]}$. HUCPVCs have the potential for regeneration and protection of central nervous system ${ }^{[14,15]}$. Low homing rate and durability are considered the limitations of cell therapy. This approach can be modified using EVs that act as carriers of informational molecules and have adequate absorption, stability, and infinite storage capacity. Therefore, EVs as a tool for cell-free therapy have the potential of being more effective than their parent cells in adjusting the manner and action of the target cell ${ }^{[16-}$ 18]. EVs and their cell sources are reported to be effective against neuronal degeneration through the reduction of apoptosis ${ }^{[19-21]}$. As a rule, the use of EVs and their MSC sources have been established in the attenuation of apoptosis and reducing lesion area in myocardial ischemia, traumatic brain injury, and spinal cord injery ${ }^{[22-24]}$.

The current investigation was designed assuming that EVs derived from HUCPVCs may also be effective for reducing apoptosis and improving functional rehabilitation in the rat model of MCAO brain ischemia.

\section{MATERIALS AND METHODS}

\section{Animals handling and surgical procedure}

Adult healthy male Wistar rats $(\mathrm{n}=24,12$ weeks old, weighing $270-300 \mathrm{~g}$ ) were purchased from the Faculty of Pharmacy, Tehran University of Medical Sciences, Tehran, Iran. The rats were kept at a stable temperature of $22{ }^{\circ} \mathrm{C}$, with a $12 \mathrm{~h} \mathrm{light/dark} \mathrm{cycle.} \mathrm{Food} \mathrm{and} \mathrm{water}$ were provided ad libitum. Cerebral ischemia was induced by left MCAO as previously reported ${ }^{[25,26]}$. Briefly, rats were anesthetized with $5.0 \%$ isoflurane (Baxter Corporation, USA), while the left common, left external, and left internal carotid arteries were exposed to a ventral midline skin incision. A siliconcoated monofilament (Doccol Co., USA) was passed through common carotid artery to MCA. The monofilament was removed one hour after the induction of MCAO. Rats were divided into four groups ( $\mathrm{n}=6$ per group): Sham, MCAO, MCAO + HUCPVCs, and MCAO + EVs. Animals in the sham group underwent the skin incision and dissection of arteries, but arterial occlusion was not performed. According to our pervious investigation ${ }^{[27]}$, at two hours after ischemia induction, the MCAO + HUCPVC and MCAO + EV groups received intracerebroventricular injection of HUCPVCs $\left(3 \times 10^{5}\right.$ cells in $5 \mu \mathrm{lPBS})$ and EVs $(50 \mu \mathrm{g}$ of EVs in $5 \mu \mathrm{l} \mathrm{PBS})$, respectively, into the left lateral ventricle with the following coordinates (from bregma: antro-posterior $=$ $-0.9 \mathrm{~mm}$, medio-lateral $=-1.8 \mathrm{~mm}$ (midline), and dorso-ventral $=3.5 \mathrm{~mm}$ deep from the dura $)^{[28]}$.

\section{Cell culture}

\section{Isolation and culture of HUCPVCs}

HUCPVCs isolated from healthy human umbilical cords (gestational age $=39$ weeks) were obtained from Arash Women's Hospital (Tehran, Iran). The cells were collected according to previous protocols ${ }^{[29]}$. In brief, the dissected umbilical cord vessels were cut into $5-\mathrm{cm}$ pieces. After incubation in $1 \mathrm{mg} / \mathrm{ml}$ of collagenase solution (Sigma-Aldrich, USA), the vessels were discarded and the solution was centrifuged (4000 $\times \mathrm{g}$ for $5 \mathrm{~min})$. HUCPVCs were suspended in alpha-MEM medium (Invitrogen, USA) containing penestrep $1 \%$ (Gibco, USA) and $10 \%$ fetal bovine serum (Gibco) and plated in T75 flasks at a density of $3 \times 10^{3}$ cells $/ \mathrm{cm}^{3}$. Next, the flasks were transferred into a $5 \% \mathrm{CO}_{2}$ incubator at $37{ }^{\circ} \mathrm{C}$ to reach 90\% confluence. The multipotent behavior of the cells was confirmed by osteogenic and adipogenic differentiation using the respective Alizarin red and Oil red $\mathrm{O}$ staining ${ }^{[30,31]}$. To evaluate the osteogenic differentiation, third passaged HUCPVCs were cultured on six-well plates in the osteogenic medium (Gibco). After 21 days, the medium was removed, and cells were fixed in $4 \%$ formaldehyde solution for 30 min. They were then rinsed in distilled water and stained with 2\% Alizarin Red solution (Gibco) for 4 min. Afterward, the wells were rinsed twice with distilled water and visualized under a light microscope. 
For adipogenic differentiation, third passaged cells were cultured on six-well plates in an adipogenic medium for 21 days. In the next step, they were washed with distilled water, fixed in $4 \%$ formaldehyde for $30 \mathrm{~min}$ and stained with $0.5 \%$ Oil red $\mathrm{O}$ solution (Gibco) at room temperature for $10 \mathrm{~min}$. Eventually, Oil Red O solution was removed, and the samples were washed immediately with distilled water and observed under light microscopy.

\section{Flow cytometry}

HUCPVCs were incubated with FITC-conjugated monoclonal antibodies against CD90 and CD45 (eBioscience, Thermo Fisher Scientific, USA) and with PE-conjugated monoclonal antibodies against CD31 and CD146 (eBioscience, Thermo Fisher Scientific). Then the cells were washed and suspended in PBS (Gibco) and assessed under a BD FACSCalibur ${ }^{\mathrm{TM}}$ (BD Biosciences, USA). The FACS data were analyzed using FlowJo software (BD Bioscience).

\section{Isolation, purification, and characterization of HUCPVCs-EVs}

When the HUCPVCs reached 70-80\% confluency, the culture medium was replaced with fetal bovine serum-free EV medium, and the conditioned medium was collected every $48 \mathrm{~h}$ from passages 3 to 5 . The cell-free conditioned medium was centrifuged at 3000 $\times \mathrm{g}$ for $10 \mathrm{~min}$ to remove cell debris. Afterwards, EVs were isolated by three steps of differential centrifugation: $20,000 \times \mathrm{g}$ for $30 \mathrm{~min}$, followed by centrifugation of supernatant for $120 \mathrm{~min}$ at 110,000 $\times \mathrm{g}$, subsequent resuspention of the pellet in $4 \mathrm{ml}$ PBS (PBS lack of $\mathrm{mg}$ and $\mathrm{Ca}$ ), and final centrifugation at $110,000 \times \mathrm{g}$ for $120 \mathrm{~min}$. The isolated EVs were characterized by $\mathrm{SEM}^{[32]}$. Moreover, the expression profiling of enriched $\mathrm{EV}$ proteins, including CD63 (1:500, ab8219), CD81 (1:500, sc-7637), and Calnexin (1:500, ab75801), was evaluated using Western blotting as described before ${ }^{[33]}$. Briefly, the EV proteins $(30 \mu \mathrm{g})$ were first isolated, measured for protein concentration by Bradford assay (Bio-Rad, USA). The extracted proteins were run on a $12 \%$ SDSPAGE, and transferred onto polyvinylidene fluoride membranes (Bio-Rad, France). The polyvinylidene fluoride membranes were blocked in Tris-buffered saline (Sigma-Aldrich) containing 5\% powdered milk at $37{ }^{\circ} \mathrm{C}$ for $1 \mathrm{~h}$ and then incubated overnight with the primary antibodies at $4{ }^{\circ} \mathrm{C}$. Next, samples were incubated with peroxidase-conjugated goat anti-rabbit secondary antibody (Bio-Rad, USA). The bands were visualized with an enhanced chemiluminescence system (ECL plus, Pierce Scientific, Waltham, MA, USA) and quantified using Total Lab Quant Analysis software (Total Lab Limited, England). The sizes of
EVs were determined using a DLS device (Malvern Instruments, Malvern, UK).

\section{TTC staining}

TTC staining was performed to determine the infarct areas of the left cortex at 24 hours after MCAO. Animals were anesthetized with isoflurane, after which using a rat brain matrix, their brains were cut into 2$\mathrm{mm}$ coronal sections and stained with $2 \%$ TTC (Sigma-Aldrich) solution for $10 \mathrm{~min}$. Coronal sections were then extended from frontal to occipital areas and photographed using a digital camera (Olympus, Japan). The infarcted areas appeared in white ${ }^{[34,35]}$.

\section{Neurobehavioral tests \\ Adhesive removal test}

The adhesive removal test was performed to assess somatosensory deficit, adhering to previous guidelines ${ }^{[36]}$. Briefly, rats were familiarized with the test before starting the MCAO. After habituation to the cages, animals were transferred to the testing room and placed in a transparent box $(36 \times 19.5 \times 18.5)$ for 5 min. Subsequently, they were taken out of the box and trained for three days to take off the yellow adhesive tapes $(1 \times 1 \mathrm{~cm})$ pasted on each forepaw. Only animals able to remove the tapes in $\leq 10$ s were selected for ischemia induction. The test was repeated at 1,3 , and 7 days after MCAO, and the time length of tape removal by the rats was recorded.

\section{EBST}

EBST is a locomotor reflexive behavior test that does not need training, as described by Borlongan et $a l .{ }^{[37]}$. The rats were left in a transparent cage $(40 \times 40$ $\times 35.5 \mathrm{~cm})$. By clutching the tail, animals were raised up to $5 \mathrm{~cm}$ from the cage surface. The left or right motion was recorded when the head of the animals deviated at $10^{\circ}$ to the sides from the midline. After the left MCAO, the rats swung mostly to the right. Control rats swung to the left or right in almost equal times, as previously documented ${ }^{[38]}$. After one swing, rats were placed in a supine position in the cages to move freely for $5 \mathrm{~min}$. All steps were repeated 14 times for each animal.

\section{IHC}

IHC staining was performed to evaluate the expressions of MAP2, Bax, and Bcl-2 at the protein level, as described earlier ${ }^{[39]}$. Briefly, brain coronal sections $(10 \mu \mathrm{m})$ were deparaffinized. They were then incubated with a medium containing $0.3 \%$ Triton (Kiazist, Iran) and $10 \%$ goat serum (Capricorn Scientific GmbH, Germany), MAP2, Bax, or Bcl-2 primary antibodies (1:100; Abcam, USA) at $4{ }^{\circ} \mathrm{C}$ overnight. After washing twice with PBS, samples 
were incubated with rabbit anti-rat FITC-conjugated secondary antibody (Abcam) in the dark at $37{ }^{\circ} \mathrm{C}$ for 30 min. Samples were again washed with PBS, followed by adding DAPI (Sigma-Aldrich) to counterstain the nuclei.

\section{Caspase-3 and -9 immunostaining}

Brain coronal sections $(10 \mu \mathrm{m})$ were deparaffinized, placed in $1 \times$ TBS (Sigma-Aldrich) solution and boiled. After reaching the boiling temperature, the sections were removed and placed in the solvent $\left(\mathrm{H}_{2} \mathrm{O}_{2}\right.$ and methanol mixture) for another $15 \mathrm{~min}$. Samples were exposed to $\mathrm{H}_{2} \mathrm{O}_{2}$ and methanol solution for $10 \mathrm{~min}$. Samples were then immersed in the blocking buffer (1\% BSA containing $0.3 \%$ Triton-X-100) for $50 \mathrm{~min}$, followed by incubation with caspase- 3 and caspase- 9 primary antibodies (1:100; Santa Cruz Biotechnology, Santa Cruz, CA). The sections were stored at $4{ }^{\circ} \mathrm{C}$ overnight. Then equal volumes $(100 \mu \mathrm{l})$ of linker rabbit anti-rat IgG (Abcam, USA), polymer, and a chromogen DAB (Sigma-Aldrich) buffer were sequentially added to the samples for 20,30 , and $5 \mathrm{~min}$, respectively. The slides were counterstained with hematoxylin and monitored by optical microscopy (Olympus). After each step, samples were washed with PBS. ImageJ software version $1.42 q$ was used to analyze the images. Images were loaded onto the Image $\mathbf{J}$ software and then oxylin and eosin DAB icon on the Image $\mathbf{J}$ software $^{[40]}$. The brightness and contrast of the images were adjusted by calculating the density of brown color areas. Caspase-positive areas stained dark brown $^{[41]}$.

\section{TUNEL assay}

The in situ Cell Death Detection Kit (Roche Applied Science, Mannheim, Germany) was used to evaluate apoptosis. The $10-\mu \mathrm{m}$ coronal sections were heated at $60{ }^{\circ} \mathrm{C}$ and washed using xylene, grading series of ethanol, and double-distilled water, in the order of their appearance. The sections were incubated with protease $\mathrm{K}$ at $37{ }^{\circ} \mathrm{C}$ for $30 \mathrm{~min}$, then placed in $1 \%$ Triton $\mathrm{X}-100$ for $10 \mathrm{~min}$. After washing with PBS, the sections were stained with the TUNEL reaction mixture at $37{ }^{\circ} \mathrm{C}$ for $\sim 1$ hour. DAPI was used to counterstain the nuclei. The stained sections were washed, and apoptosis was calculated as the ratio of TUNEL-positive neurons to the total neurons. Counting was carried out twice, in a blinded fashion. Next, 10 fields from each slide (three sections for each animal) were randomly chosen and counted.

\section{Nissl staining}

On day seven after MCAO, rats were anesthetized and sequentially perfused with $150 \mathrm{ml}$ of normal saline and $250 \mathrm{ml}$ of $4 \%$ paraformaldehyde (Merck, Germany). Brain samples were removed and stored in $4 \%$ paraformaldehyde at $4{ }^{\circ} \mathrm{C}$ and then embedded in paraffin and sectioned. Brain coronal sections $(10 \mu \mathrm{m})$ were deparaffinized in xylene with two changes for $10 \mathrm{~min}$ and hydrated in $100 \%$ alcohol twice for $5 \mathrm{~min}$, 95\% alcohol for $3 \mathrm{~min}$, and $70 \%$ alcohol for $3 \mathrm{~min}$. Sections were rinsed in tap water and distilled water and stained with $1 \%$ cresyl violet solution (SigmaAldrich) for 3-10 $\min ^{[42]}$.

\section{qRT-PCR}

The expression of the MAP2 gene was evaluated by qRT-PCR. Using TRIzol® Reagent (Qiagen, Germany), total RNA was collected from fresh cerebral tissues. Afterward, $1 \mu \mathrm{g}$ of mRNA was converted to cDNA by reverse transcription using the First Strand cDNA Synthesis Kit (Fermentas, USA). For further analysis, primers, cDNA, and PCR reagents (polymerase, dNTP, magnesium, and buffer; $5 \times$ HOT FIREPol® EvaGreen ${ }^{\circledR}$ qPCR Mix Plus [ROX] $1 \mathrm{ml}$, Solis Bio Dyne, Estonia) were placed in the RT-PCR machine. Primer sequences of MAP2 and GAPDH primers were as follows: MAP2 forward (19 bp): CTT TTG TT GCT CGG GAT T and MAP2 reverse (20 bp): GGG TCA CTA AAC TGC CAC CT as well as GAPDH forward (22 bp): AAG TTC AAC GGC ACA GTC AAG G and GAPDH reverse (22 bp): CAT ACT CAG CAC CAG CAT CAC C. Samples were incubated at $95{ }^{\circ} \mathrm{C}$ for $15 \mathrm{~min}$ for initial polymerase activation. Then the following three steps were taken: denaturation, at $95{ }^{\circ} \mathrm{C}$ for $15 \mathrm{~s}$; annealing, at $60{ }^{\circ} \mathrm{C}$ for $20 \mathrm{~s}$; elongation, at $72{ }^{\circ} \mathrm{C}$ for $20 \mathrm{~s}$. The $\Delta \Delta \mathrm{Ct}$ method was used for the relative quantification of data and normalization of GAPDH. The obtained data were represented as fold change mRNA expression compared to the sham group.

\section{Statistical analysis}

Kolmogorov-Smirnov test was used to check the normal distribution of the obtained data. The entire data analysis was performed using a two-way analysis of variance (ANOVA), followed by the Tukey's post hoc test. Results were expressed as mean $\pm \mathrm{SD}$, and comparisons were considered statistically significant at $p$ values less than 0.05 .

\section{Ethical statement}

The above-mentioned treatment/sampling protocols were approved by the Research Ethics Committee of Tehran University of Medical Science, Tehran, Iran (ethical code: IR.TUMS.MEDICINE. REC.1396.3189). 


\section{RESULTS}

HUCPVC and HUCPVC-EV isolation and characterization

After nine days of primary culture, the adherent cells exhibited a fibroblastic spindle-shape morphology and showed confluency and propensity to differentiate into osteogenic and adipogenic lineages (Fig. 1A-1D). According to the results of flow cytometry, HUCPVCs indicated a high rate of expression for MSC marker CD90 (96.3\%) and pericyte marker CD146 (88.9\%). Meanwhile, the cells were negative for hematopoietic cell marker CD45 $(2.11 \%)$ and endothelial cell marker CD31 (0.19\%), as represented in Figure 1E. Based on

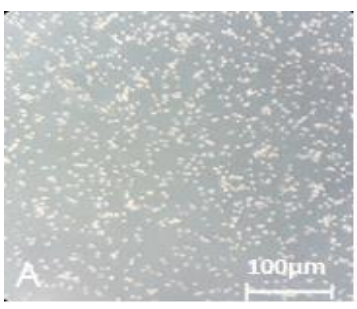

(E)

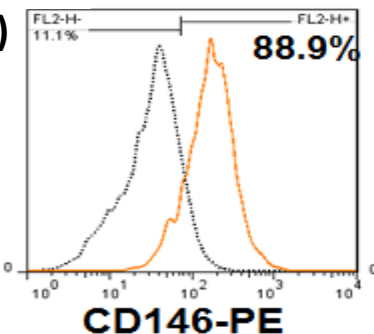

(F)

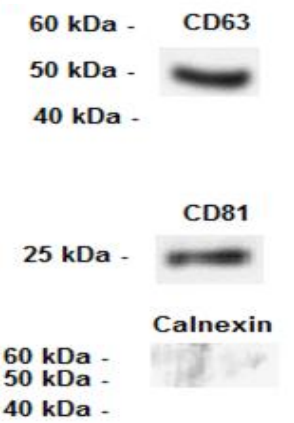

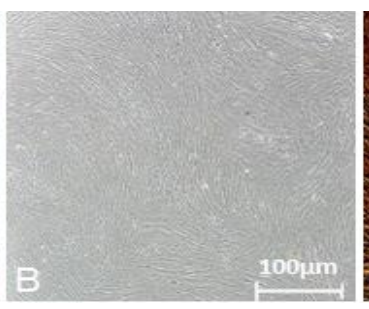

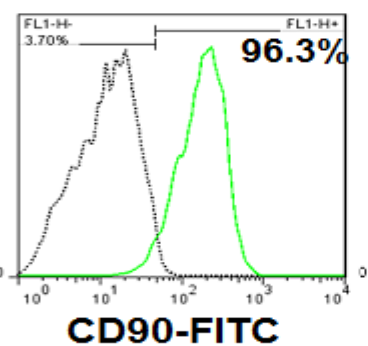

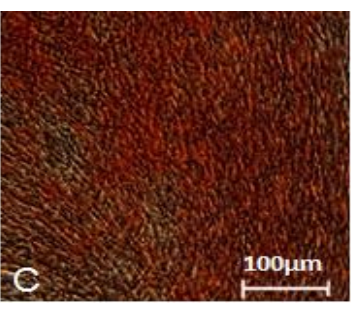
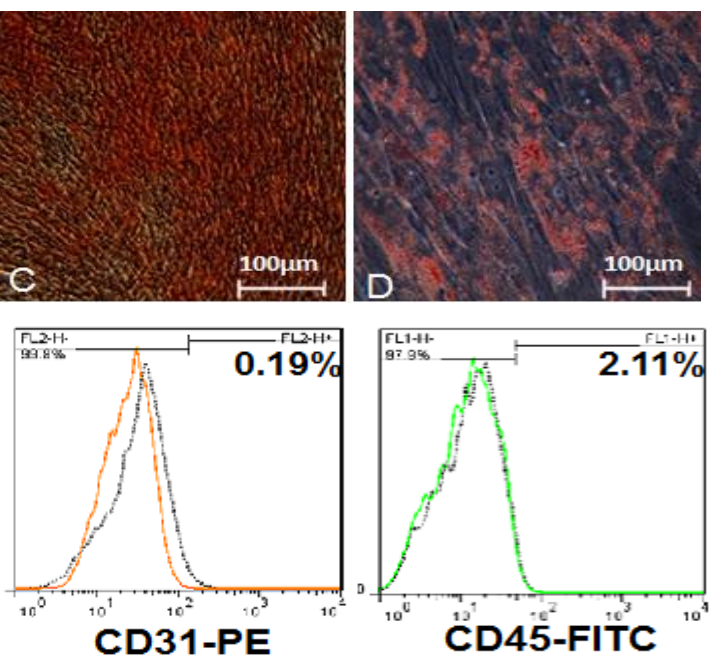

(G)

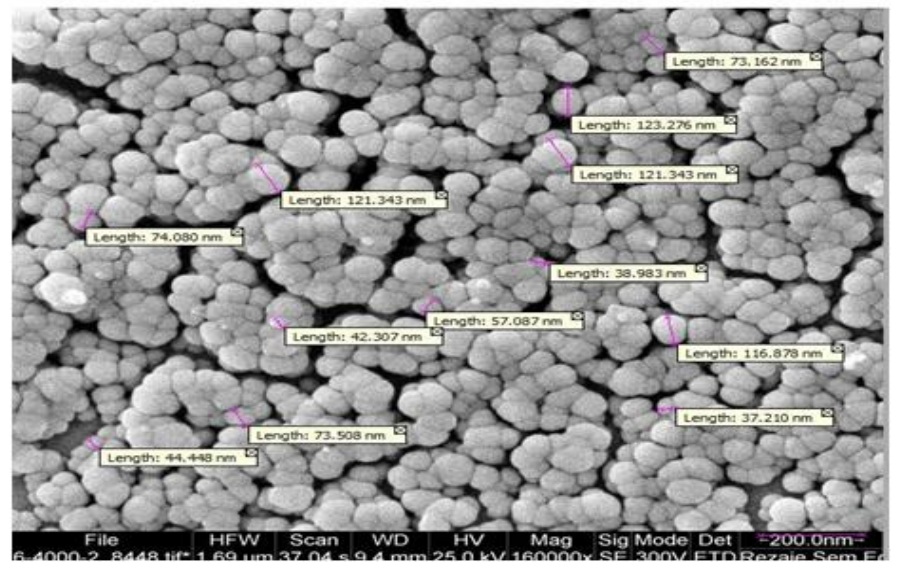

(H)

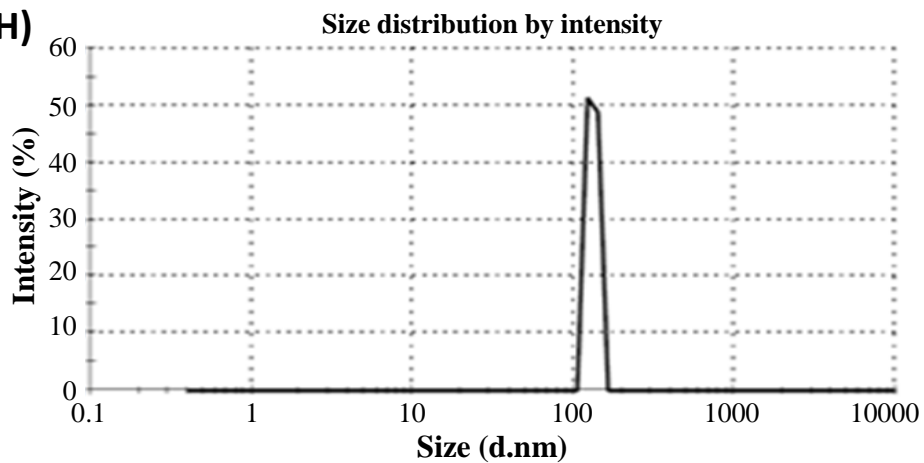

Fig. 1. Characteristics of HUCPVCs-derived EVs. (A and B) HUCPVCs under routine cultivation conditions at passages 0 and 3 ( $\times 100$ magnification); (C and D) multi-potential feature of the HUCPVCs, attested by the differentiation of the cells into osteogenic (Alizarin red staining) and adipogenic (Oil red O staining) lineages $(\times 100)$; (E) flow cytometry for evaluating the expressions of cell surface markers in HUCPVCs; (F) Western blot results for the detection of protein expression of surface markers in EVs. EVs highly expressed CD63 and CD81, but Calnexin was not expressed in the particles; (G) SEM images showing that the HUCPVC-derived particles had spherical shape; (H) DLS histogram demonstrating that EVs had variable sizes ranging from 35-200 nm. 
the Western blot results, HUCPVCs-EVs expressed CD63- and CD81-specific markers of EVs, while the cells were negative for Calnexin (Fig. 1F). The results of SEM (Fig. 1G) and DLS (Fig. 1H) demonstrated that the particles had spherical morphology (SEM outcomes) with a size range of 35-200 nm. EVs were revived from frozen stocks.

\section{TTC staining and neurobehavioral functions}

TTC staining was performed on samples from $24 \mathrm{~h}$ post MCAO induction, to confirm the MCAO model. The infarcted area in the left hemisphere cortex appeared in white (Fig. 2A), denoting the induction of ischemia, whereas in the sham-operated group, the cortex appeard in red.

\section{Adhesive removal test}

No notable differences existed between all the groups in the elimination of sticky tapes on the first day after MCAO of sticky tapes on the first day after
MCAO ( $p<0.05)$. On day 3, however, the time spent for the removal of the adhesive tapes in the MCAO + $\mathrm{EV}$ group $(48.11 \pm 6.64)$ reduced significantly compared to the MCAO + HUCPVC $(58.33 \pm 5.26)$ and MCAO $(63.00 \pm 3.24)$ groups $(p<0.001)$. On day seven post ischemia, the time reduced even more in the $\mathrm{MCAO}+\mathrm{EV}(25.22 \pm 3.15)$ and MCAO + HUCPVC $(29.55 \pm 2.83)$ groups compared to the MCAO group ( $p<0.001$ ), indicating that the HUCPVCs EVs have positive effects on the improvement of sensorimotor impaired by ischemia. No significant differences found between EV-treated and HUCPVC-treated groups (Fig. 2B).

\section{Assessment of asymmetrical motor and locomotor behavior}

There were no significant differences in the left swing between the HUCPVCs (4.3 \pm 0.86$)$ and EVs $(3.8 \pm 1.26)$ therapy groups compared to the MCAO group $(3.7 \pm 0.97 ; p<0.05)$ on day three post
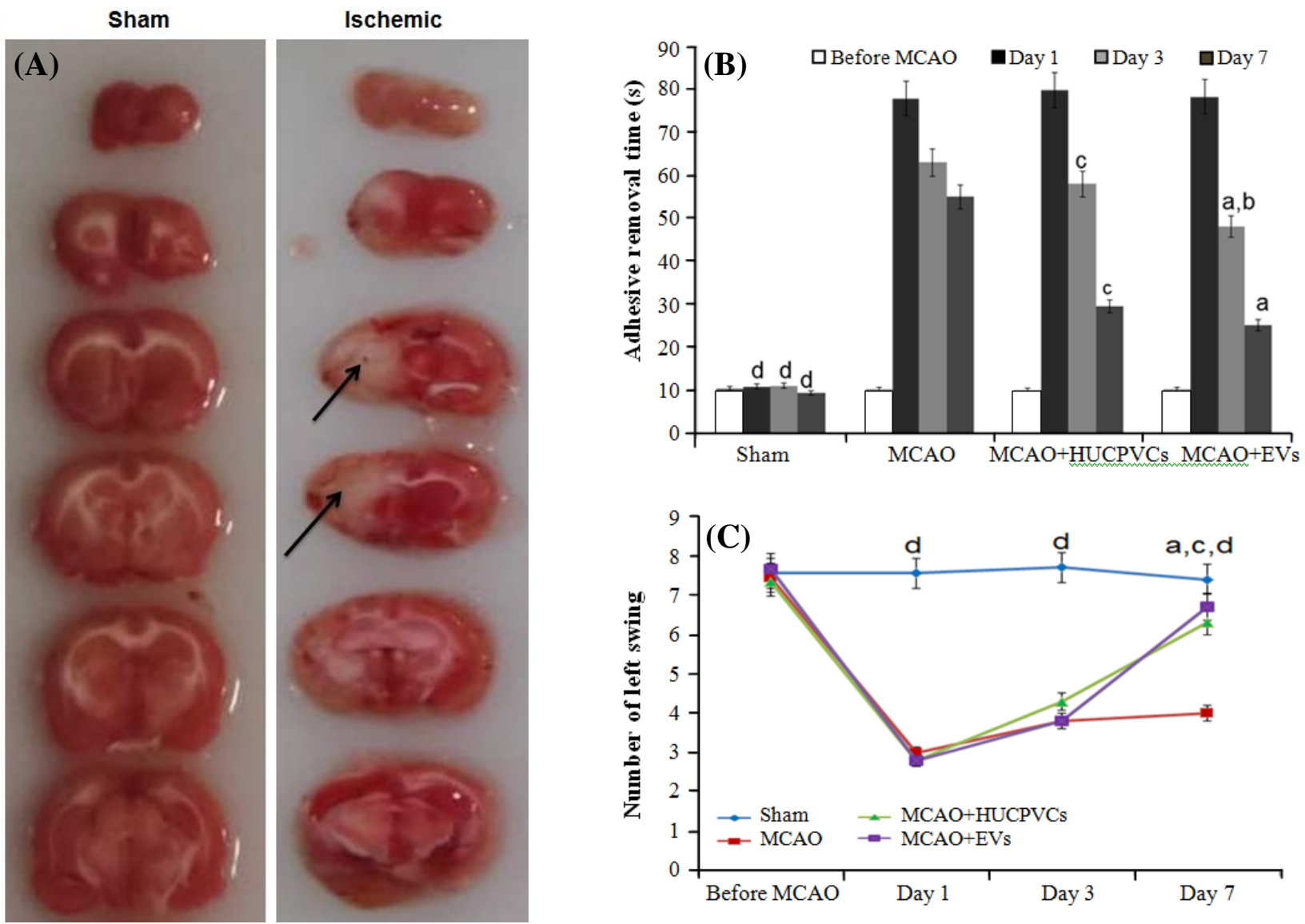

Fig. 2. TTC staining of seven sequential coronal brain slices at $24 \mathrm{~h}$ after left MCAO and the effects of EVs derived from HUCPVCs on neurobehavioral functions. (A) Ischemic rats revealed white regions (arrows) in the left side of cortex; (B and C) results of the adhesive removal test and EBST at the $1^{\text {st }}, 3^{\text {rd }}$, and $7^{\text {th }}$ days after MCAO. All data are shown as mean \pm SD $($ ANOVA, $n=$ six/group, and significant differences are indicated by lowercase letters $(p<0.05 ; \mathrm{a}, \mathrm{MCAO}+\mathrm{EVs}$ vs. MCAO; b, MCAO + EVs vs. MCAO + HUCPVCs; c, MCAO + HUCPVCs vs. MCAO; d, sham vs. all MCAO groups). 
ischemia. In contrast, a notable rise was in the left swing for the MCAO + EVs $(6.7 \pm 0.7)$ and MCAO + HUCPVC $(6.3 \pm 0.7)$ groups compared to the MCAO group $(4.1 \pm 1.05)$ on day seven post MCAO $(p<$ $0.001)$. However, the difference between the MCAO + $\mathrm{EV}$ and $\mathrm{MCAO}+\mathrm{HUCPVC}$ groups was not statistically significant (Fig. 2C).

\section{Bax/Bcl-2 ratio}

IHC was performed to determine $\mathrm{Bcl}-2$ and $\mathrm{Bax}$ protein expressions (Fig. 3). According to the quantitative results, the $\mathrm{Bax} / \mathrm{Bcl}-2$ ratio was reduced significantly in the EV- $(p<0.001)$ and HUCPVC ( $p<$ $0.05)$ treated groups, as compared to the MCAO group. $\mathrm{Bax} / \mathrm{Bcl}-2$ ratio in $\mathrm{EV}$-treated group also reduced significantly in comparison to that of the HUCPVCtreated group $(p<0.05)$.

\section{HUCPVCs-EVs effect on caspase-3 and -9 protein expression}

Caspase-3 (23.5 \pm 3.33) and $-9(14.26 \pm 1.54)$ expressions underwent a significant reduction in the EV-treated group, as compared to the MCAO + HUCPVCs (caspase-3, $37.41 \pm 1.68$ and caspase-9, $36.75 \pm 2.48 ; p<0.01$ ) as well as MCAO (caspase-3, $64 \pm 13.49$ and caspase-9, $40 \pm 7.07 ; p<0.001)$ groups, evaluated at day seven post MCAO. The expression of caspase-3 also decreased in the HUCPVC-treated group, compared to the MCAO group $(p<0.001$; (Fig. 4).

\section{TUNEL staining}

TUNEL is a technique used for detecting apoptotic cells in histological sections. The amount of TUNEL positive cells was markedly raised in all test groups (63 \pm 4.1 ), which underwent ischemia, in reference to the sham-treated group $(6.5 \pm 0.5 ; p<0.001)$. In the $\mathrm{MCAO}+\mathrm{EV}$ group $(34.3 \pm 0.57)$, The proportion of the apoptotic cells to the total cells was decreased significantly compared to the MCAO $(64.5 \pm 3.27)$ and $\mathrm{MCAO}+\mathrm{HUCPVC}(43.6 \pm 3.05)$ groups in the IBZ (for both $p<0.001$ ). Meanwhile, in the HUCPVCtreated group, the quantity of TUNEL positive cells was significantly reduced compared to the MCAO group $(p<0.001$; Fig. 5).

\section{Effects of HUCPVCs-EVs on dead neurons in the IBZ}

Nissl staining was assessed to evaluate the number of dead neurons. Based on the obtained results, the $\mathrm{MCAO}+\mathrm{EV}$ group $(5.3 \pm 1.75)$ had a significant reduction in the number of dead neurons compared to the MCAO + HUCPVCs $(15.16 \pm 3.3)$ and MCAO $(25.83 \pm 4.62)$ groups (for both $p<0.001$; Fig. 6).

\section{The effects of HUCPVC-EVs on neuronal density in the IBZ}

Data from Figure 7 show the findings for MAP2 expression in the studied groups. The EV-treated rats had a meaningful rise in the amount of MAP2 ${ }^{+}$neurons $(59.5 \pm 3.72)$ compared to the MCAO (Fig. 7A and 7B; $p<0.001)$. The MAP2 gene expression exhibited a 4.6fold increase in the EV-treated group $(1.2 \pm 0.77)$ compared to the MCAO group $(0.26 \pm 0.073 ; p<$ 0.001; Fig. 7C).

\section{DISCUSSION}

This research aimed to investigate the impacts of HUCPVCs-EVs on functional neuronal recovery, prevention of further damage, and neuronal apoptosis associated with ischemia. Our outcomes showed that EVs therapy after MCAO decreased neuronal apoptosis, increased neuronal density, reduced dark neurons and the infarct size and improved the sensorimotor function. Ample evidence exists on the efficacy of cell-based therapy for stroke ${ }^{[43,44]}$. MSCsEVs are assumed as the main paracrine effects of MSCs and a reliable supersede with lower oncological risks $^{[45]}$. Our results also support the studies elucidating that EVs secreted by MSCs provide a mechanism for participation in cellular communication with other cells, as well as protein and RNA transfer for tissue repair $^{[46,47]}$.

The present study disclosed that HUCPVCs-EVs improved sensory and motor performance in the ischemic rats. Xin et al. ${ }^{[48]}$ demonstrated that EVs derived from bone marrow MSCs improve neurological function and neuronal regeneration in the animal model of ischemia. These outcomes are consistent with the indirect effects of MSCs, emphasizing that MSCs are likely to exert their paracrine effects via the secretion of the EVs ${ }^{[49]}$. These vesicles are included in cell synergy, signaling, and adjusting cell metabolism and consequence tissue metabolism in the body ${ }^{[50]}$. Rare homing and endurance and tumorigenicity are barriers to cell therapy. This approach can be modified using EVs that are nanosize vesicles and carriers of informational molecules having sufficient absorption, establishment, and unlimited storage capacity ${ }^{[20]}$. Improvement of sensorimotor function after cell therapy and their cellfree extracts, namely EVs, is related to neurogenesis, neovascularization, and restraint of apoptosis and increase the livability of cerebral cells after $\mathrm{MCAO}^{[51-53]}$.

Apoptosis plays a pivotal role in neuronal death after stroke ${ }^{[3,54]}$. Apoptotic cells are degraded in an 
(A)

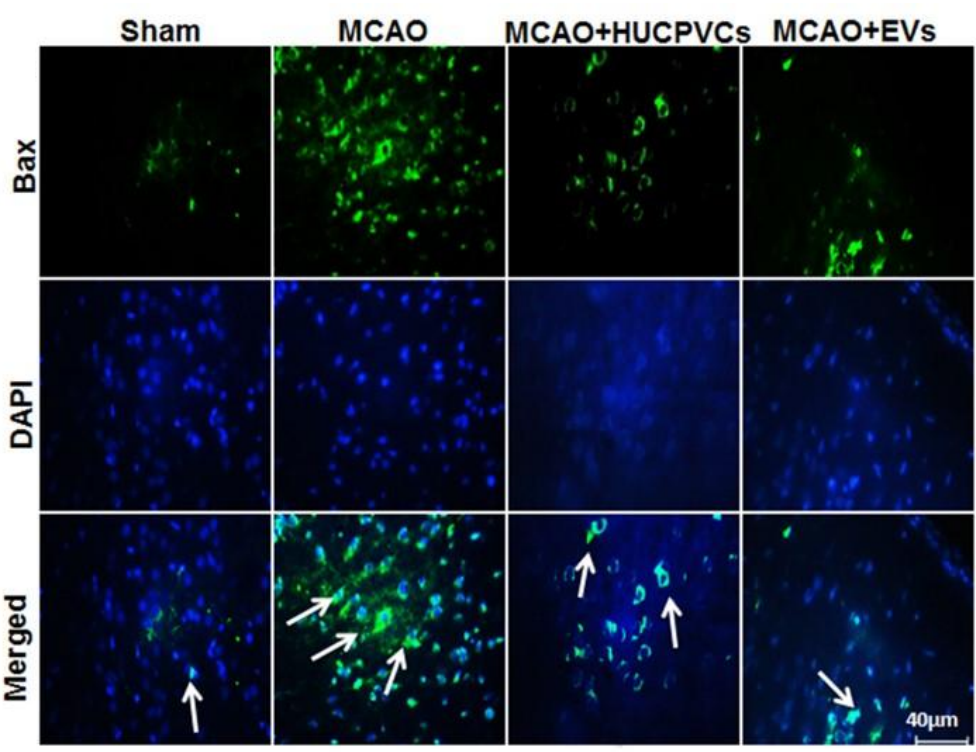

(B)
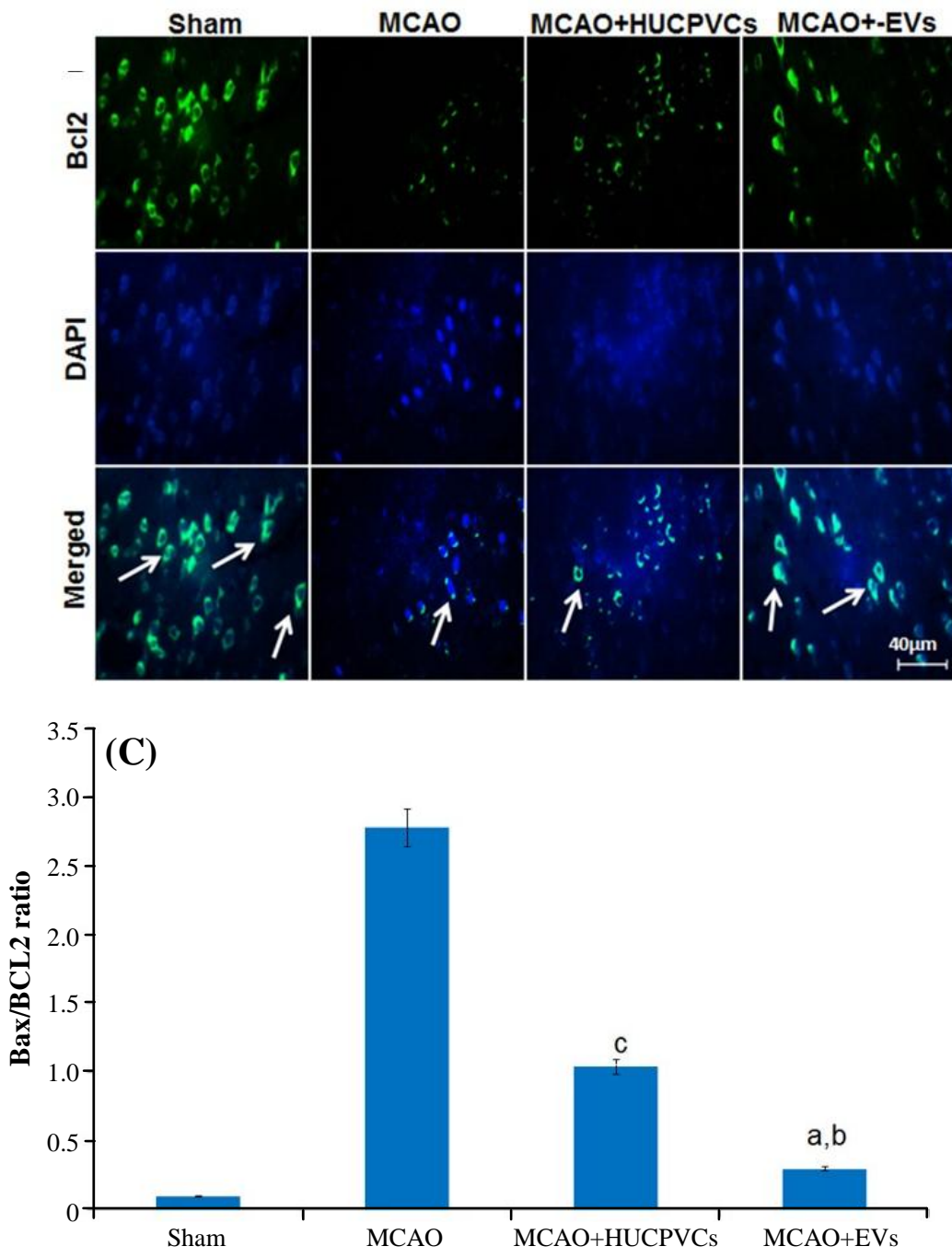

Fig. 3. Effects of HUCPVC-EVs on Bax and Bcl-2 expression in the rat model of MCAO. The Figure shows qualitative and quantitative immunofluorescence outcomes. Arrows indicate the Bax and Bcl-2 positive cells. All data are represented as mean \pm SD (ANOVA, $\mathrm{n}=3$ /group). Significant differences are demonstrated by lowercase letters ( $p<0.05$; a, MCAO + EVs vs. MCAO; b, MCAO + EVs vs. MCAO + HUCPVCs; c, MCAO + HUCPVCs vs. MCAO; d, sham vs. all MCAO groups). 

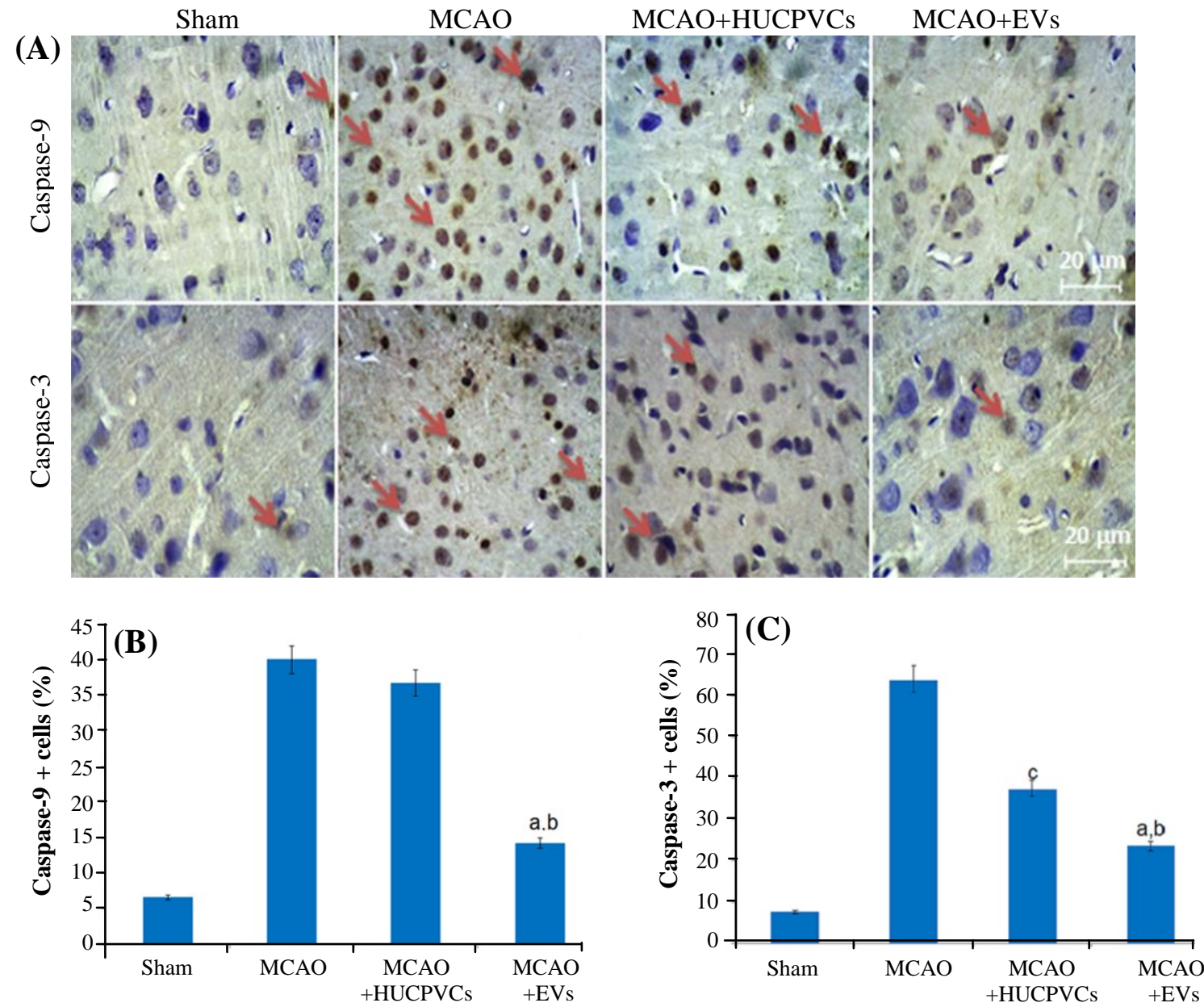

Fig. 4. Caspase- 9 and caspase- 3 protein expressions measured after the administration of EVs derived from HUCPVCs in rats underwent MCAO ischemia induction. (A) IHC images of the caspase-9 and caspase-3. Arrows demonstrate the caspase-9 and caspase-3 positive cells. (B and C) Quantitative results for caspase 9 and 3, respectively, extracted from histological images using Image $\mathrm{J}$ software by measuring the intensity of brown staining areas. $(\mathrm{n}=3$ /group, $p<0.05)$. All data are presented as mean $\pm \mathrm{SD}$ (ANOVA, $p<0.05$ ). Significant differences are shown by lowercase letters $(p<0.05$; a, MCAO + EVs vs. MCAO; b, MCAO + EVs vs. MCAO + HUCPVCs; c, MCAO + HUCPVCs vs. MCAO).

organized way to minimize the suffering and disruption of neighbor cells ${ }^{[55]}$. Joerger-Messerli et al. ${ }^{[20]}$ showed that EVs derived from Wharton's jelly MSCs reduced apoptosis induced by perinatal hypoxia-ischemia. The results of our research revealed that the HUCPVCsEVs promoted their neuroprotective effects through the attenuation of apoptosis. We realized that the quantity of TUNEL influenced cells decreased significantly in the EVs-treated group. Concurrent with the reduction of TUNEL-positive cells in the MCAO + EV group, down-regulation of Bax protein and up-regulation of Bcl-2 protein were detected in the present study. This result is in concordance with the study carried out by Huang et al. ${ }^{[2]}$ who found that the MSCs-EVs administration unregulated Bcl-2 in SCI rats. The Bcl2 family proteins (Bax and Bcl-2) control and regulate the intrinsic (or mitochondrial) pathway of apoptosis ${ }^{[56]}$. By localizing in the mitochondrial outer membrane, Bcl-2 protein plays an essential role in the cell survival via the inhibition of pro-apoptotic Bax protein ${ }^{[57]}$ and through the increased Bax/Bcl-2 ratio at different times after ischemia/reperfusion injury predisposes neural cells to apoptosis ${ }^{[58,59]}$. Complementary and similar to these findings, evaluation of caspase- 3 and -9 proteins revealed a noticeable decrease in the ischemic rats receiving EVs. Caspases are proteases associated with the process of programmed cell death ${ }^{[60]}$. Similarly, results of our research exhibited a meaningful diminution in the number of dark neurons for the EVs-treated rats, suggesting the protective effect of this therapeutic approach in improving neuronal recovery and reduction of neuronal cell death; this result is in line with the findings of other studies reported for $\mathrm{SCI}^{[61,62]}$. Finally, studying MAP2 gene and protein expression in the IBZ displayed a raise in the EVs-treated group in 
(A)

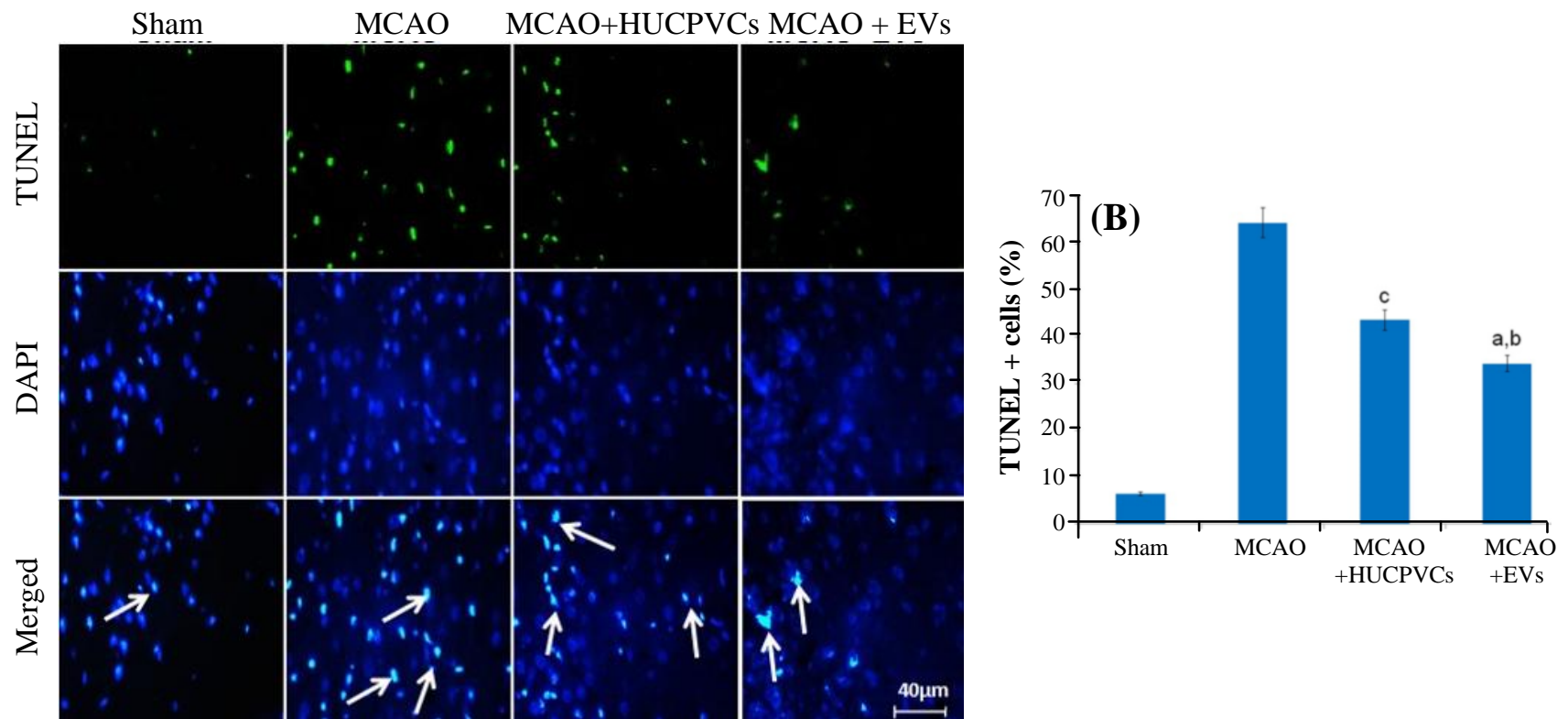

Fig. 5. TUNEL assay used for the detection of apoptosis after EV administration to the rats underwent MCAO ischemia induction. (A) TUNEL-labeled cells (marked by arrows) at day seven after MCAO; (B) quantification and statistical analysis of the TUNELpositive cells. Data are shown as mean \pm SD (ANOVA, $p<0.05 ; \mathrm{n}=3$ /group). Significant differences are presented by lowercase letters ( $p<0.001 ; \mathrm{a}, \mathrm{MCAO}+\mathrm{EV}$ s vs. MCAO; b, MCAO + EVs vs. MCAO + HUCPVCs; c, MCAO + HUCPVCs vs. MCAO).

comparison with the MCAO. EVs and secretome of MSCs are reported to increase the density of MAP2 ${ }^{+}$ mature neurons inside the body and laboratory environment $^{[14,23]}$, which is possibly associated with the rebuilding of injured neurons in the IBZ ${ }^{[63]}$.

Overall, it is reasonable to assert that $\mathrm{EVs}$ are possibly appropriate candidates for regulating apoptosis and improving neuronal functional recovery in the ischemic brain. Furthermore, it can be stated that this cell-free approach is more effective than cell therapy for such purposes. The results of this study provide evidence favoring the efficacy of the application of EVs derived from HUCPVCs for improving sensorimotor function in the ischemic rats, possibly through the regulation of apoptosis. This strategy could benefit targeting brain diseases, using cell-free extracts in the clinic.

CONFLICT OF INTEREST. None declared.

(A)
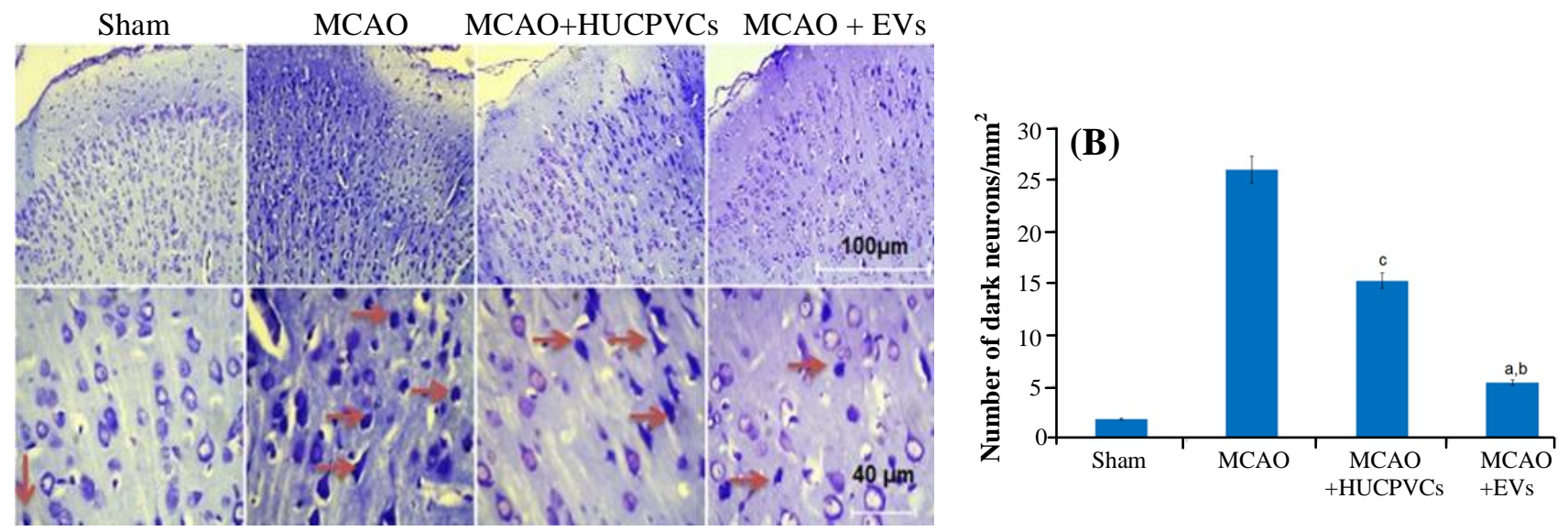

Fig. 6. Effects of EVs on viability of neurons in the rat model of cerebral ischemia induced by MCAO. (A-B) Histological images and quantitative results obtained from Nissl staining using Image $\mathbf{J}$ software by counting the number of dark neurons. Data are shown as mean $\pm \mathrm{SD}$ (ANOVA, $p<0.05 ; \mathrm{n}=3$ /group). Significant differences are presented by lowercase letters $(p<0.05 ; \mathrm{a}, \mathrm{MCAO}+\mathrm{EVs}$ vs. MCAO; b, MCAO + EVs vs. MCAO + HUCPVCs; c, MCAO + HUCPVCs vs. MCAO). 
(A)
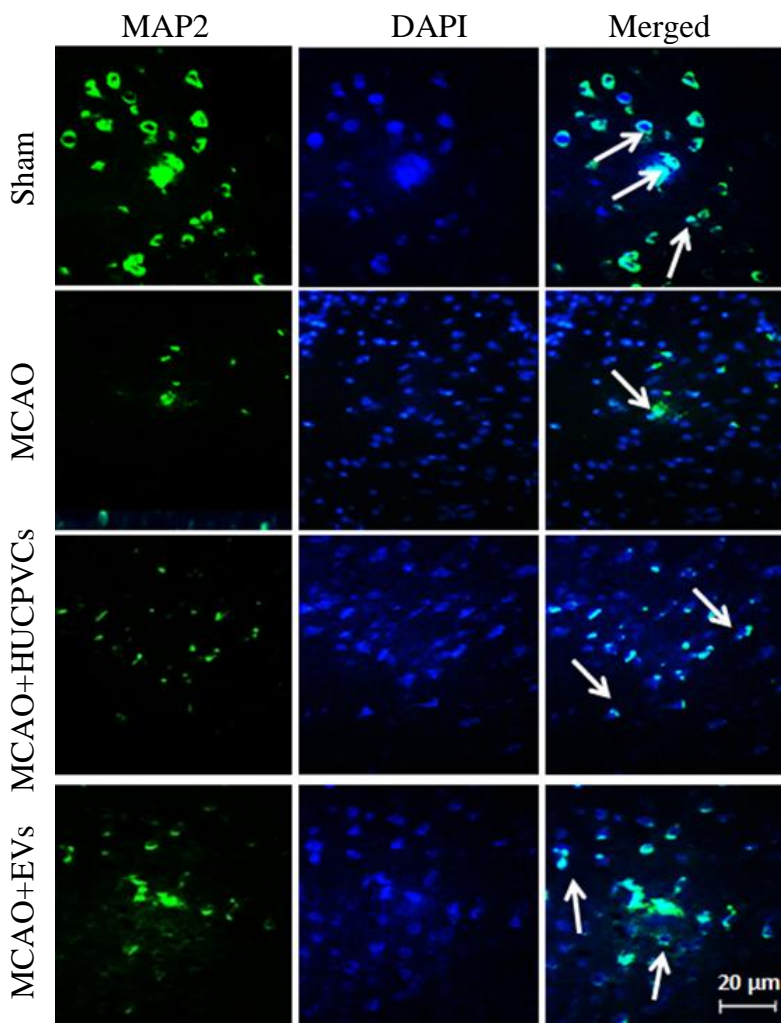

(B)

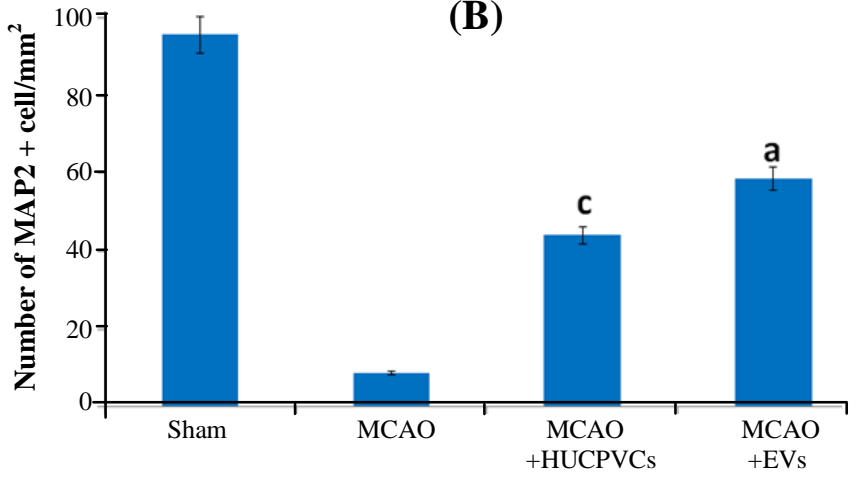

(C)

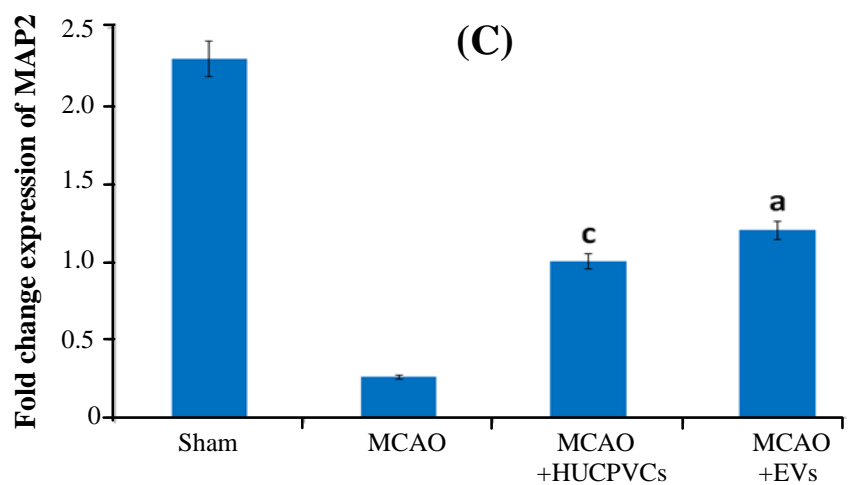

Fig. 7. Effects of EVs on the expression of MAP2 gene and protein expression in rats underwent MCAO ischemia induction. (A and B) results from IHC; (C) qRT-PCR findings. Data are shown as mean \pm SD (ANOVA, $p<0.05 ; \mathrm{n}=3$ /group). Significant differences are represented by lowercase letters $(p<0.05$; a, MCAO + EVs vs. MCAO; b, MCAO + EVs vs. MCAO + HUCPVCs; c, MCAO + HUCPVCs vs. MCAO; d, sham vs. all MCAO groups).

\section{REFERENCES}

1. Gu N, Dong Y, Tian Y, Di Z, Liu Z, Chang M, Jia X, Qian Y, Zhang W. Anti-apoptotic and angiogenic effects of intelectin-1 in rat cerebral ischemia. Brain research bulletin 2017; 130: 27-35.

2. Li Y, Cheng Q, Hu G, Deng T, Wang Q, Zhou J, Su X. Extracellular vesicles in mesenchymal stromal cells: A novel therapeutic strategy for stroke. Experimental and therapeutic medicine 2018; 15(5): 4067-4079.

3. Radak D, Katsiki N, Resanovic I, Jovanovic A, SudarMilovanovic E, Zafirovic S, A Mousad S, R Isenovic E. Apoptosis and acute brain ischemia in ischemic stroke. Current vascular pharmacology 2017; 15(2): 115-122.

4. Bretón RR, Rodríguez JCG. Excitotoxicity and oxidative stress in acute ischemic stroke, Acute Ischemic Stroke. Reterieved from: https://www. intechopen.com/books/acute-ischemic-stroke/ excitotoxicity-and-oxidative-stress-in-acute-ischemic-stroke.

5. Li Y, Yang GY. Pathophysiology of Ischemic Stroke. Translational Research in Stroke. Translational Medicine Research.Singapore: Springer; 2017.

6. Ashkenazi A, Fairbrother WJ, Leverson JD, Souers AJ. From basic apoptosis discoveries to advanced selective BCL-2 family inhibitors. Nature reviews drug discovery 2017; 16(4): 273-284.

7. Kang MH, Reynolds CP. Bcl-2 inhibitors: targeting mitochondrial apoptotic pathways in cancer therapy. Clinical cancer research 2009; 15(4): 1126-1132.

8. Thornberry NA, Lazebnik Y. Caspases: enemies within. Science 1998; 281(5381): 1312-1316.

9. Schulz JB, Weller M, Moskowitz MA. Caspases as treatment targets in stroke and neurodegenerative diseases. Annals of neurology 1999; 45(4): 421-429.

10. Sinden JD, Hicks C, Stroemer P, Vishnubhatla I, Corteling R. Human neural stem cell therapy for chronic ischemic stroke: charting progress from laboratory to patients. Stem cells development 2017; 26(13): 933-947.

11. Venkat P, Shen Y, Chopp M, Chen J. Cell-based and pharmacological neurorestorative therapies for ischemic stroke. Neuropharmacology 2018; 134(Pt B): 310-322.

12. Monteforte A, Lam B, Sherman MB, Henderson K, Sligar AD, Spencer A, Tang B, Dunn AK, Baker AB. Glioblastoma exosomes for therapeutic angiogenesis in peripheral ischemia. Tissue engineering part A 2017; 23(21-22): 1251-1261.

13. Nawaz M, Fatima F, Vallabhaneni KC, Penfornis P, Valadi H, Ekström K, Kholia S, Whitt JD, Fernandes 
JD, Pochampally R, Squire JA, Camussi G. Extracellular vesicles: Evolving factors in stem cell biology. Stem cells international 2016; 2016:1073140.

14. Teixeira FG, Carvalho MM, Neves-Carvalho A, Panchalingam KM, Behie LA, Pinto L, Sousa N, Salgado AJ. Secretome of mesenchymal progenitors from the umbilical cord acts as modulator of neural/glial proliferation and differentiation. Stem cell reviews and reports 2015; 11(2): 288-297.

15. Fraga JS, Silva NA, Lourenco AS, Goncalves V, Neves NM, Reis RL, Rodrigues AJ, Manadas B, Sousa N, Salgado AJ. Unveiling the effects of the secretome of mesenchymal progenitors from the umbilical cord in different neuronal cell populations. Biochimie 2013; 95(12): 2297-2303.

16. S ELA, Mager I, Breakefield XO, Wood MJ. Extracellular vesicles: biology and emerging therapeutic opportunities. Nature reviews drug discovery 2013; 12(5): 347-357.

17. Lai RC, Arslan F, Lee MM, Sze NS, Choo A, Chen TS, Salto-Tellez M, Timmers L, Lee CN, El Oakley RM, Pasterkamp G, de Kleijn DP, Lim SK. Exosome secreted by MSC reduces myocardial ischemia/ reperfusion injury. Stem cell research 2010; 4(3): 214222.

18. Eirin A, Zhu XY, Puranik AS, Woollard JR, Tang H, Dasari S, Lerman A, Van Wijnen AJ, Lerman LO. Integrated transcriptomic and proteomic analysis of the molecular cargo of extracellular vesicles derived from porcine adipose tissue-derived mesenchymal stem cells. PLoS one 2017; 12(3): e0174303.

19. Calió ML, Marinho DS, Ko GM, Ribeiro RR, Carbonel AF, Oyama LM, Ormanji M, Guirao TP, Calió PL, Reis LA. Transplantation of bone marrow mesenchymal stem cells decreases oxidative stress, apoptosis, and hippocampal damage in brain of a spontaneous stroke model. Free radical biology and medicine 2014; 70: 141-154.

20. Joerger-Messerli MS, Oppliger B, Spinelli M, Thomi G, Di Salvo I, Schneider P, Schoeberlein A. Extracellular vesicles derived from Wharton's jelly mesenchymal stem cells prevent and resolve programmed cell death mediated by perinatal hypoxiaischemia in neuronal cells. Cell transplantation 2018; 27(1): 168-180.

21. Liu W, Wang Y, Gong F, Rong Y, Luo Y, Tang P, Zhou Z, Zhou Z, Xu T, Jiang T. Exosomes derived from bone mesenchymal stem cells repair traumatic spinal cord injury by suppressing the activation of A1 neurotoxic reactive astrocytes. Journal of neurotrauma 2019; 36(3): 469-484.

22. Zhao Y, Sun X, Cao W, Ma J, Sun L, Qian H, Zhu W, $\mathrm{Xu} \mathrm{W}$. Exosomes derived from human umbilical cord mesenchymal stem cells relieve acute myocardial ischemic injury. Stem cells international 2015; 2015: 761643

23. Zhang Y, Chopp M, Meng Y, Katakowski M, Xin H, Mahmood A, Xiong Y. Effect of exosomes derived from multipluripotent mesenchymal stromal cells on functional recovery and neurovascular plasticity in rats after traumatic brain injury. Journal of neurosurgery 2015; 122(4): 856-867.

24. Huang JH, Yin XM, Xu Y, Xu CC, Lin X, Ye FB, Cao Y, Lin FY. Systemic administration of exosomes released from mesenchymal stromal cells attenuates apoptosis, Inflammation, and promotes angiogenesis after spinal cord injury in rats. Journal of neurotrauma 2017; 34(24): 3388-3396.

25. Zendedel A, Habib P, Dang J, Lammerding L, Hoffmann S, Beyer C, Slowik A. Omega-3 polyunsaturated fatty acids ameliorate neuroinflammation and mitigate ischemic stroke damage through interactions with astrocytes and microglia. Journal of neuroimmunology 2015; 278: 200-211.

26. Mokhtari T, Akbari M, Malek F, Kashani IR, Rastegar T, Noorbakhsh F, Ghazi-Khansari M, Attari F, Hassanzadeh G. Improvement of memory and learning by intracerebroventricular microinjection of $\mathrm{T} 3$ in rat model of ischemic brain stroke mediated by upregulation of BDNF and GDNF in CA1 hippocampal region. DARU journal of pharmaceutical sciences 2017; 25(1): 4

27. Mahdavipour M, Hassanzadeh G, Seifali E, Mortezaee K, Aligholi H, Shekari F, Sarkoohi P, Zeraatpisheh Z, Nazari A, Movassaghi S, Akbari M. Effects of neural stem cell-derived extracellular vesicles on neuronal protection and functional recovery in the rat model of middle cerebral artery occlusion. Cell biochemistry andfunction 2020; 38(4): 373-383.

28. Paxinos G, Watson C. The Rat Brain in Stereotaxic Coordinates. $7^{\text {th }}$ Edition. Amesterdam: Elsevier; 2013.

29. Sarugaser R, Ennis J, Stanford WL, Davies JE. Isolation, propagation, and characterization of human umbilical cord perivascular cells (HUCPVCs). Stem cells in regenerative medicine 2009: 482: 269-279.

30. Eom J, Feisst V, Ranjard L, Loomes K, Damani T, Jackson-Patel V, Locke M, Sheppard H, Narayan P, Dunbar PR. Visualization and quantification of mesenchymal cell adipogenic differentiation potential with a lineage specific marker. Journal of visualized experiments 2018; (133): 57153.

31. Jaiswal N, Haynesworth SE, Caplan AI, Bruder SP. Osteogenic differentiation of purified, culture-expanded human mesenchymal stem cells in vitro. Journal of cellular biochemistry 1997; 64(2): 295-312.

32. Sunkara V, Woo HK, Cho YK. Emerging techniques in the isolation and characterization of extracellular vesicles and their roles in cancer diagnostics and prognostics. The analyst 2016; 141(2): 371-381.

33. Weng Y, Sui Z, Shan Y, Hu Y, Chen Y, Zhang L, Zhang Y. Effective isolation of exosomes with polyethylene glycol from cell culture supernatant for in-depth proteome profiling. Analyst 2016; 141(15): 4640-4646.

34. Swanson RA, Morton MT, Tsao-Wu G, Savalos RA, Davidson C, Sharp FR. A semiautomated method for measuring brain infarct volume. Journal of cerebral blood flow and metabolism 1990; 10(2): 290-293.

35. Zhang A, Bai Y, Hu Y, Zhang F, Wu Y, Wang Y, Zheng $\mathrm{P}, \mathrm{He} \mathrm{Q}$. The effects of exercise intensity on $\mathrm{p}$ - 
NR2B expression in cerebral ischemic rats. Canadian journal of neurological sciences 2012; 39(5): 613-618.

36. Bouet V, Boulouard M, Toutain J, Divoux D, Bernaudin M, Schumann-Bard P, Freret T. The adhesive removal test: a sensitive method to assess sensorimotor deficits in mice. Nature protocols 2009; 4(10): 1560-1564.

37. Borlongan $\mathrm{CV}$, Hida $\mathrm{H}$, Nishino $\mathrm{H}$. Early assessment of motor dysfunctions aids in successful occlusion of the middle cerebral artery. Neuroreport 1998; 9(16): 36153621.

38. Pan Y, Zhang H, Acharya AB, Patrick PH, Oliver D, Morley JE. Effect of testosterone on functional recovery in a castrate male rat stroke model. Brain research 2005; 1043(1-2): 195-204.

39. Enayati A, Yassa N, Mazaheri Z, Rajaei M, Pourabouk M, Ghorghanlu S, Basiri S, Khori V. Cardioprotective and anti-apoptotic effects of Potentilla reptans L. Root via Nrf2 pathway in an isolated rat heart ischemia/reperfusion model. Life sciences 2018; 215: 216-226.

40. Fuhrich DG, Lessey BA, Savaris RF. Comparison of HSCORE assessment of endometrial beta integrin subunit expression with digital HSCORE using computerized image analysis (ImageJ). Analytical and quantitative cytopathology and histopathology 2013; 35(4): 210-216.

41. Haines DM, Chelack BJ. Technical considerations for developing enzyme immunohistochemical staining procedures on formalin-fixed paraffin-embedded tissues for diagnostic pathology. Journal of veterinary diagnostic investigation 1991; 3(1): 101-112.

42. Zhu H, Zhang Y, Shi Z, Lu D, Li T, Ding Y, Ruan Y, $\mathrm{Xu}$ A. The neuroprotection of liraglutide against ischaemia-induced apoptosis through the activation of the PI3K/AKT and MAPK pathways. Scientific reports 2016; 6: 26859

43. Sugiyama Y, Sato Y, Kitase Y, Suzuki T, Kondo T, Mikrogeorgiou A, Horinouchi A, Maruyama S, Shimoyama Y, Tsuji M, Suzuki S, Yamamoto T, Hayakawa M. Intravenous administration of bone marrow-derived mesenchymal stem cell, but not adipose tissue-derived stem cell, ameliorated the neonatal hypoxic-Ischemic brain Injury by changingcerebral inflammatory state in rat. Frontiers in neurology 2018; 9: 757.

44. Sabbaghziarani F, Mortezaee K, Akbari M, Kashani IR, Soleimani M, Moini A, Ataeinejad N, Zendedel A, Hassanzadeh G. Retinoic acid-pretreated Wharton's jelly mesenchymal stem cells in combination with triiodothyronine improve expression of neurotrophic factors in the subventricular zone of the rat ischemic brain injury. Metabolic brain disease 2017; 32(1): 185193.

45. Wiklander OP, Nordin JZ, O'Loughlin A, Gustafsson Y, Corso G, Mager I, Vader P, Lee Y, Sork H, Seow Y, Heldring N, Alvarez-Erviti L, Smith CI, Le Blanc K, Macchiarini P, Jungebluth P, Wood MJ, Andaloussi SE. Extracellular vesicle in vivo biodistribution is determined by cell source, route of administration and targeting. Journal of extracellular vesicles 2015; 4: 26316.

46. Hirshman BR, Kras RT, Akers JC, Carter BS, Chen CC. Extracellular Vesicles in Molecular Diagnostics: An Overview with a Focus on CNS diseases. Advances in clinical chemistry 2016; 76: 37-53.

47. Maumus M, Jorgensen C, Noel D. Mesenchymal stem cells in regenerative medicine applied to rheumatic diseases: role of secretome and exosomes. Biochimie 2013; 95(12): 2229-2234.

48. Xin H, Li Y, Cui Y, Yang JJ, Zhang ZG, Chopp M. Systemic administration of exosomes released from mesenchymal stromal cells promote functional recovery and neurovascular plasticity after stroke in rats. Journal of cerebral blood flow and metabolism 2013; 33(11): 1711-1715.

49. Xin H, Katakowski M, Wang F, Qian JY, Liu XS, Ali MM, Buller B, Zhang ZG, Chopp M. MicroRNA-1792 cluster in exosomes enhance neuroplasticity and functional recovery after stroke in rats. Stroke 2017; 48(3): 747-753.

50. Phinney DG, Pittenger MF. Concise review: MSC-derived exosomes for cell-free therapy. Stem cells 2017; 35(4): 851-858.

51. Lee JY, Kim E, Choi S-M, Kim D-W, Kim KP, Lee I, Kim H-S. Microvesicles from brain-extract-treated mesenchymal stem cells improve neurological functions in a rat model of ischemic stroke. Scientific reports 2016; 6: 33038 .

52. Doeppner TR, Herz J, Görgens A, Schlechter J, Ludwig A-K, Radtke S, de Miroschedji K, Horn PA, Giebel B, Hermann DM. Extracellular vesicles improve post-stroke neuroregeneration and prevent postischemic immunosuppression. Stem cells translational medicine 2015; 4(10): 1131-1143.

53. Xiao B, Chai Y, Lv S, Ye M, Wu M, Xie L, Fan Y, Zhu $\mathrm{X}$, Gao Z. Endothelial cell-derived exosomes protect SH-SY5Y nerve cells against ischemia/reperfusion injury. International journal of molecular medicine 2017; 40(4): 1201-1209.

54. Hedayatpour A, Shiasi M, Famitafreshi H, Abolhassani F, Ebrahimnia P, Mokhtari T, Hassanzaeh G, Karimian M, Nazparvar B, Marefati N, Tarzjani MD. Coadministration ofprogesterone and melatonin attenuates ischemia-induced hippocampal damage in Rats. Journal of molecular neuroscience 2018; 66(2): 251260.

55. Broughton BR, Reutens DC, Sobey CG. Apoptotic mechanisms after cerebral ischemia. Stroke 2009; 40(5): e331-e339.

56. Pena-Blanco A, Garcia-Saez AJ. Bax, Bak and beyondmitochondrial performance in apoptosis. The FEBS journal 2018; 285(3): 416-431.

57. Liu QS, Deng R, Li S, Li X, Li K, Kebaituli G, Li X, Liu R. Ellagic acid protects against neuron damage in ischemic stroke through regulating the ratio of $\mathrm{Bcl}-$ 2/Bax expression. Applied physiology, nutrition, and metabolism 2017; 42(8): 855-860.

58. Aboutaleb N, Shamsaei N, Rajabi H, Khaksari M, Erfani S, Nikbakht F, Motamedi P, Shahbazi A. 
Protection of Hippocampal CA1 neurons against ischemia/reperfusion injury by exercise preconditioning via modulation of $\mathrm{Bax} / \mathrm{Bcl}-2$ ratio and prevention of caspase-3 activation. Basic and clinical neuroscience 2016; 7(1): 21-29.

59. Wang C, Liu M, Pan Y, Bai B, Chen J. Global gene expression profile of cerebral ischemia-reperfusion injury in rat MCAO model. Oncotarget 2017; 8(43): 74607-74622.

60. Julien O, Wells JA. Caspases and thir substrates. Cell death and differentiation 2017; 24(8): 1380-1389.

61. Wang L, Pei S, Han L, Guo B, Li Y, Duan R, Yao Y, Xue B, Chen X, Jia Y. Mesenchymal stem cell-derived exosomes reduce A1 astrocytes via downregulation of phosphorylated NFkB P65 subunit in spinal cord injury. Cellular Physiology and biochemistry 2018; 50(4): 1535-1559.

62. Lu Y, Zhou Y, Zhang R, Wen L, Wu K, Li Y, Yao Y, Duan R, Jia Y. Bone Mesenchymal Stem Cell-Derived Extracellular Vesicles Promote recovery Following Spinal Cord Injury via Improvement of the Integrity of the Blood-Spinal Cord Barrier. Frontiers in neuroscience 2019; 13: 209.

63. Li Y, Jiang N, Powers C, Chopp M. Neuronal damage and plasticity identified by microtubule-associated protein 2, growth-associated protein 43 , and cyclin D1 immunoreactivity after focal cerebral ischemia in rats. Stroke 1998; 29:(9): 1972-1979. 